\title{
Design of the Wireless Intelligent Comprehensive Physique Test System Shunwei $\mathrm{Wu}^{1, \mathrm{a}}$ \\ ${ }^{1}$ College of Physics and Electronic Engineering, Taishan University, Taian 271021 China \\ aemail:wushun123@163.com
}

\begin{abstract}
Keywords: Contactless IC Card; Gas Flow Sensors; Draw-wire Displacement Sensors; Comprehensive Physique; MCU
\end{abstract}

\begin{abstract}
Due to the actual problems of the poor real-time performance on the original physique test equipment, a kind of wireless intelligent comprehensive physique test system is studied. By using the high precision special signal disposal and $\mathrm{A} / \mathrm{D}$ conversion module, the anthropometric parameters are achieved. Through the GSM and wireless Wi-Fi module, the physical datum is transmitted to the mobile phone or tablet. Through the radio frequency identification module, the information of the measured man will be storied, and identified by testing. The physical information can be print out by the way of the micro printer.
\end{abstract}

\section{Introduction}

At present, with the continuous improvement of living standards, health is becoming more and more attention to their own. The formation causes about the poor physical student are analyzed from the natural environment, social environment, family education and the factors on education policy, and suggestions that how to avoid these problems are given[1]-[3].These papers analyzed the way to solve the problem from theory. But whether the constitution is good or bad, this needs to use the special measuring instrument to measure. A kind of comprehensive physique survey and health evaluation management system is designed and researched [4]. It can achieve the integrating qualitative detection and management of students. Ma [5] studied the physical measurement and evaluation system of students based on a web network platform, it can complete the comprehensive evaluation on the student's constitution through the network in recent years. Both of $\mathrm{Wu}$ [4] and Ma [5] can achieve the measurement and management of students' physique constitution in the form of the network and database, but for some students, they need to login in the network system to query their own physical condition, so the real-time capability is not strong. Therefore, in this paper, a students' wireless comprehensive physique testing system is designed, which has the strong real-time capability.

\section{The function of system}

(1) The campus card can be brushed, the corresponding card number displays on the LCD.

(2) The system can measure the body height, the range is from $1500 \mathrm{~mm}$ to1900 $\mathrm{mm}$, and the accuracy is $5.0 \mathrm{~mm}$, the error is $\pm 5.0 \mathrm{~mm}$.

(3) The system can measure the body weight, the range is from $30 \mathrm{~kg}$ to180 $\mathrm{kg}$, the precision is $0.01 \mathrm{~kg}$, the error is $\pm 0.1 \mathrm{~kg}$.

(4) The system can calculate the vital capacity, the range is from $1000 \mathrm{ml}$ to $10000 \mathrm{ml}$, the accuracy is $\pm 0.1 \mathrm{ml}$. The error is $\pm 1 \mathrm{ml}$, and it can automatically recognize whether the index is qualified by the ratio of vital capacity and weight.

(5) The system can complete the wireless datum transmission, all measured datum and credit card information can be transmitted to the android tablet by using the wireless transmission module, and the datum can be exported.

(6) The system can realize the receiving and transmission of data and messages, all personal health indexes can be transmitted to their phone. 


\section{The overall design and measurement principle}

\section{The overall design}

The overall system includes the MCU hardware detection and data sending module (called lower computer) and the mobile phone or tablet receive module (known as upper computer), the overall structure is shown in figure 1 , it is a parameter measurement module, and can complete the display of weight, vital capacity, height. The human physique parameters display on the mobile phone or a tablet, the other measured information can display too, such as IC number, name, age, and so on.

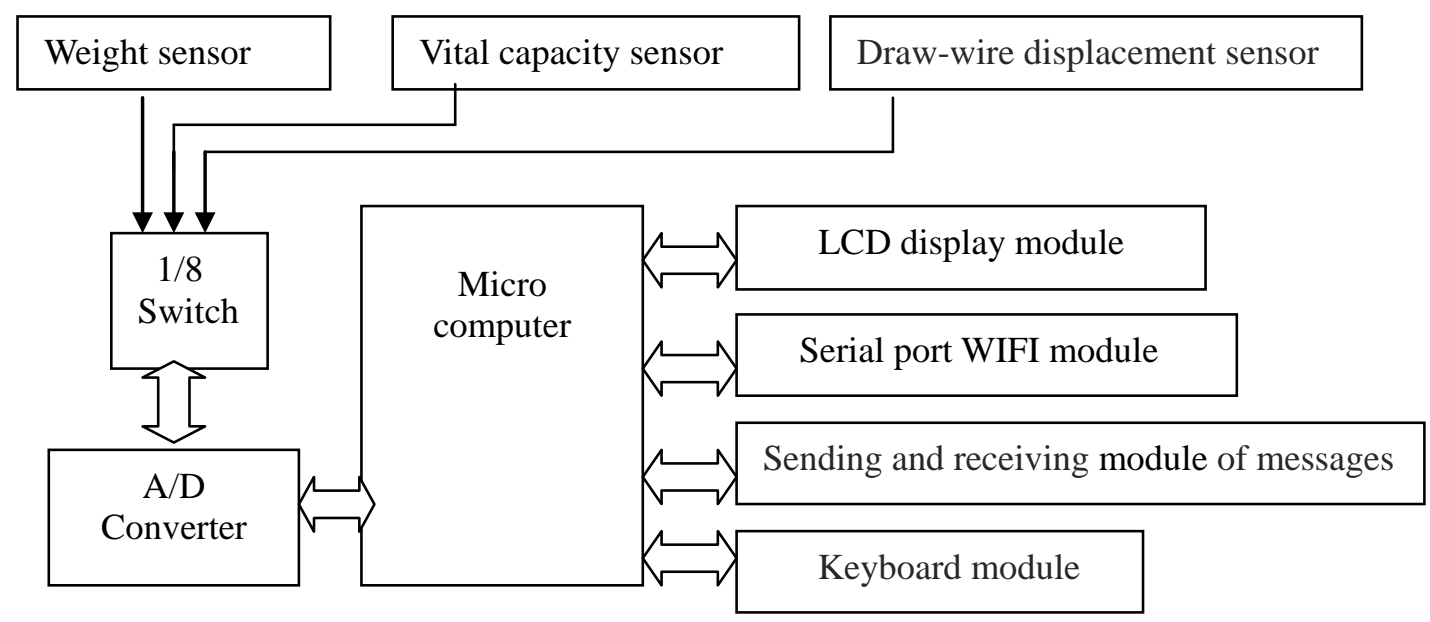

Fig.1 The overall structure diagram of system

\section{Measurement principle and calculation}

(1) The measuring principle of weight

The double parallel cantilever beam and strain type weighing sensor is adopted. It is that the strain gauge is pasted on the sensitive type of elastic element, when the elastic element is stressed, it can produce the corresponding deformation. The resistance change caused by the force will be converted into the voltage changes of the measurement circuit. Using the special A/D converter chip HX711, the analog voltage is converted to the digital quantity, it is transmitted to single chip microcomputer. Through the software conversion, the weight of measured object can be obtained. It is expressed in $T$, and can be calculated by formula (1).

$$
T=\frac{170}{16777216} \times A D_{-} \text {date }
$$

(2) The measurement principle of vital capacity

The big flow sensor AWM720P1 is adopted, the air is collected from $0 \mathrm{l} / \mathrm{min}$ to $200 \mathrm{l} / \mathrm{min}$, and it is converted into the voltage value from $1 \mathrm{v}$ to $5 \mathrm{v}$. Through the A/D converter chip ADC0832, the signal is converted into the digital quantity, which is transmitted to MCU, and then converted into the vital capacity by software in the single-chip microcomputer, and the result displays on the LCD. Using the T0 timer, the sampling time interval is 0.5 second, all the measured values are accumulated, and eventually the vital capacity is achieved. It is expressed in $F$, and can be calculated by formula (2).

$$
F=\frac{100 \times A D_{-} \text {date } 1-45}{113}
$$

(3) The measuring principle of height

The draw-wire displacement sensor is used, it can convert the displacement amount into the pulse signal, and these signals are generated by the incremental encoder. When the movement occurs, the rope is stretched and contracted. The wheel turns the encoder, the electric signal is generated that the output strength is proportional to the rope mobile distance, the displacement of moving object is concluded by the way of measuring the output signal. It is expressed in $S G$, and 
can be calculated by formula (3).

$$
S G=\frac{1000}{256} \times A D_{-} \text {date } 10
$$

\section{The design of main module}

(1) The read card circuit design of campus card

The special read card module MF RC522 is used. It is a contactless IC card read or write chip that includes some advantages, such as low voltage, low cost, and small volume, it is a good choice in design of the intelligent instrument and portable handheld device. The circuit diagram is shown in figure 2. The SPI bus is adopted when it is linked with single-chip microcomputer circuit. MOSI, MISO and SCK connect with the P2.0, P2.1 and P2.2 of MCU respectively.

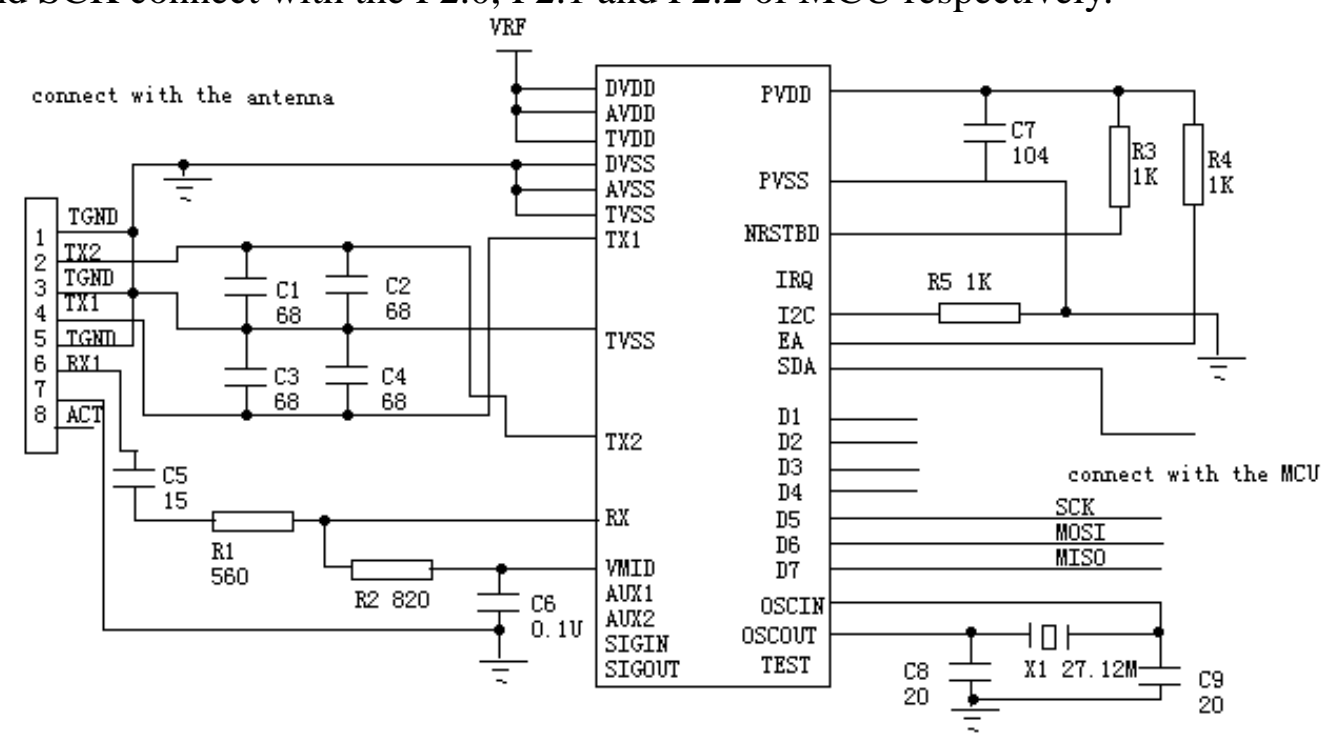

Fig.2 The principle diagram of connection circuit between RC522 and MCU

(2) The special A/D conversion module of weight

Because the output of weighing sensor is the weak signal differential formation, a dedicated signal conditioning and A/D converter chip HX711 is used in this design, it is a 24-bits A/D converter chip that is designed for high precision electronic scale, which can complete the precision measurement, four wires are used to connect with the sensor, including AVDD, AGND, INA + and INA -. The $\mathrm{I}^{2} \mathrm{C}$ bus is used to connect with MCU, DOUT and PD_SCK connect with P2.3 and P2.4 of MCU respectively. The principle diagram of connection circuit between the HX711 and MCU is shown in figure 3.

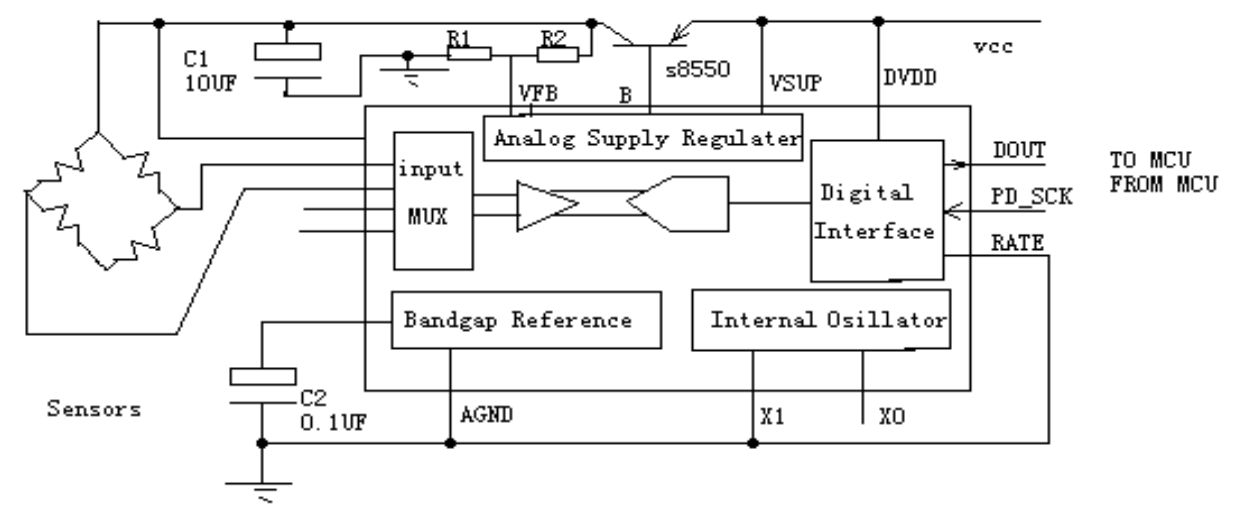

Fig.3 The principle diagram of connection circuit between HX711 and MCU 


\section{The software design}

(1) The software composition and process of lower computer

The IC card information is read at first, according to the test datum obtained from vital capacity ,height and weight, the datum of comprehensive physique is got by using the calculation formula in the program, and these data are sent to the mobile phone through the GSM program, and they are transmitted to the tablet through the wireless communication program in upper computer.

(2) The software design of upper computer

The mobile phone or a tablet is used to display the human physique parameters and other information from lower computer, the display interface is shown in figure 4, the JAVA language is used in software design of the upper computer.

***********************************************

card numerous:

The comprehensive physique test system

vital capacity:

$\mathrm{ml}$

weight:

$\mathrm{kg}$

height:

$\mathrm{cm}$

the physique station:

$* * * * * * * * * * * * * * * * * * * * * * * * * * * * * * * * * * * * * * * *$

Fig.4 The display interface of data from upper computer

(3) The format specification and function description of communication data

The serial data formation is FF AA \# \# \# \# \# \# \# \# \# \#;

Description: FF and AA are the synchronization head. The first byte is on behalf of the unit of data, the concrete representation is shown as follow, 0 is on behalf of the card number, 1 is the vital capacity, its unit is ml, 2 denotes the weight, its unit is $\mathrm{kg}, 3$ means height, its unit is $\mathrm{cm}$. The second byte of data is on behalf of the position of the decimal point, 0 indicates an integer, 1 is on behalf of one decimal point, 2 means two decimal points. The third to the fifth bytes are three bytes of effective data, they are all hexadecimal number.

(4) The communication functional description

By using the serial port and Wi-Fi conversion module, the data are sent to the tablet by the single chip microcomputer.

The JAVA programming language is used in the software design of upper computer, an APK program is designed by using this language, and the datum is from the Wi-Fi module. This program can display the corresponding value in the corresponding position.

The measuring data can be checked and exported in the form of a document, for example, these datum can be printed by the printer.

\section{Test results and data analysis}

Five students are randomly selected for the sampling measurement of individual comprehensive physique. Everyone brushes their own campus card at first, after the information is inputted, the system measures their height, weight and vital capacity in turn, and then the parameter values are calculated automatically by program, comparing with the standard data, each person's comprehensive physique condition is achieved. The measurement parameter is shown in table 1.

We can see from the table 1, all the indexes of height, weight and vital capacity can meet the design requirement, the system is good for measuring people's comprehensive physique conditions, the important reference basis is provided for people to understand their own physical station. 
Table 1 The comprehensive physique parameter measurement table

\begin{tabular}{|c|c|c|c|c|c|c|c|c|c|c|}
\hline \multirow{2}{*}{$\begin{array}{l}\text { Tested } \\
\text { Student }\end{array}$} & \multirow{2}{*}{ sex } & \multicolumn{3}{|c|}{ Height $(\mathrm{cm})$} & \multicolumn{3}{|c|}{ Weight（kg） } & \multicolumn{3}{|c|}{ Lung capacity（ml） } \\
\hline & & $\begin{array}{c}\text { measured } \\
\text { value }\end{array}$ & $\begin{array}{l}\text { standard } \\
\text { value }\end{array}$ & Error & $\begin{array}{c}\text { measured } \\
\text { value }\end{array}$ & $\begin{array}{l}\text { Standard } \\
\text { value }\end{array}$ & Error & $\begin{array}{c}\text { measured } \\
\text { value }\end{array}$ & $\begin{array}{l}\text { Standard } \\
\text { value }\end{array}$ & Error \\
\hline 1 & $\mathrm{~F}$ & 178.2 & 178 & 0.2 & 72.01 & 72.23 & 0.22 & 3958.2 & 3958.7 & 0.5 \\
\hline 2 & $\mathrm{~F}$ & 172.7 & 173 & 0.3 & 55.53 & 55.21 & 0.32 & 4365.6 & 4365.9 & 0.3 \\
\hline 3 & $\mathrm{~F}$ & 181.3 & 181 & 0.3 & 79.41 & 79.24 & 0.17 & 4427.8 & 4427.1 & 0.7 \\
\hline 4 & $\mathrm{M}$ & 169.1 & 169 & 0.1 & 56.42 & 56.26 & 0.16 & 3450.9 & 3450.7 & 0.2 \\
\hline 5 & $\mathrm{M}$ & 162.6 & 162 & 0.6 & 53.68 & 53.35 & 0.33 & 3276.5 & 3276.4 & 0.1 \\
\hline
\end{tabular}

\section{Conclusion}

By using the high precision A/D conversion module, the comprehensive measurement of human physique parameters is achieved on the height, weight and vital capacity. By using the wireless $\mathrm{Wi}-\mathrm{Fi}$ and GSM module, the real-time testing data is sent to the person being measured in order to understand their own physical condition in time, and the necessary preventive measures are adopted to improve the current physique station, it is a certain positive meaning to improve the quality of people's lives.

\section{Acknowledgment}

In this paper, the corresponding author of this paper is Shunwei WU. The research was sponsored by the Research Foundation of Science and Technology of Taian City (No.20122058), the Shandong Excellent Young Scientist Research Award Fund (No.BS2011DX037), the Research Foundation of Science and Technology of Taian City (No.20140629-1), the Special Funds for Postdoctoral Innovative Projects of Shandong Province (No.201203055), and the National college students' innovative entrepreneurial training plan (No.201410453004).

\section{References}

[1] Shengli Liu. Thinking of the phenomenon about the increasing poor physique students in school [J], teaching and the educational reform, 2009.1:41- 42

[2] Siyuan Ma. Research on Physical Deterioration of Primary and Middle School Students in China and Its Social Causes [D]. Beijing sports university, 2012,

[3] Yan Chen. The Survey on Health and Nutrition of Primary and Secondary School Students in Different Areas of Chongqing [D],Third military medical university, 2013.

[4] Guogui Wu, Dingyi Liu. Design and Development on Student Physique Measurement and Evaluation Network Management system [J], Journal of Capital University of Physical Education, 2012, 24 (1) : 88-92

[5] Bingzhang Ma. Physical measurement and evaluation system of students based on web network platform [D], 2010. 